\title{
Treating Imatinib-Resistant Leukemia: The Next Generation Targeted Therapies
}

\author{
Michael R. Burgess ${ }^{1}$ and Charles L. Sawyers ${ }^{1,2,3, *}$ \\ ${ }^{1}$ Molecular Biology Institute, ${ }^{2}$ Howard Hughes Medical Institute, ${ }^{3}$ Division of \\ Hematology and Oncology, Department of Medicine, The David Geffen School of \\ Medicine, University of California, Los Angeles \\ E-mail: mike.burgess@ucla.edu, csawyers@mednet.ucla.edu
}

Received August 29, 2005; Revised July 28, 2006; Accepted July 31, 2006; Published August 11, 2006

Imatinib (Gleevec/STI-571/CGP57148B, Novartis) is a small-molecule, tyrosine kinase inhibitor developed to target BCR-ABL, C-Kit, and PDGF-R. Through inhibition of these oncogenic kinases, imatinib is effective in the treatment of BCR-ABL-positive leukemia, gastrointestinal stromal tumor, and hypereosinophilic syndrome, respectively. However, clinical success of imatinib is hampered by acquired resistance that may occur through several mechanisms including kinase domain mutation, target amplification, and activation of alternate signaling pathways. Strategies to overcome resistance have included targeting BCR-ABL stability and downstream signaling pathways important for tumor growth. Additional work has shown that new BCR-ABL kinase inhibitors with increased potency or alternate conformation-binding properties can target imatinib resistance. This review focuses on the mechanisms of imatinib resistance and the strategies currently being developed to overcome clinical resistance.

KEYWORDS: BCR-ABL, resistance, imatinib, kinase inhibitors, chronic myelogenous leukemia (CML), gastrointestinal stromal tumor (GIST), hypereosinophilic syndrome (HES)

\section{THE DEVELOPMENT OF IMATINIB}

Chronic myelogenous leukemia (CML) is a disorder that results from the malignant transformation of pluripotent hematopoietic stem cells[1]. Clinically, the disease progresses through distinct stages, starting with a chronic phase that progresses into an accelerated, rapidly fatal stage termed "blast crisis". The disease is characterized by the Philadelphia $(\mathrm{Ph})$ chromosome, a $\mathrm{t}(9 ; 22)$ translocation resulting in the expression of BCR-ABL, a constitutively active, cytoplasmic tyrosine kinase[2,3,4]. The $\mathrm{t}(9 ; 22)$ rearrangement is present in more than $95 \%$ of CML patients and about half of patients with adult-onset acute lymphoblastic leukemia (ALL) $[1,5,6]$.

Multiple experimental models have demonstrated the central role of BCR-ABL in leukemogenesis. In vitro culture systems demonstrated that BCR-ABL can transform immature hematopoietic cells, some fibroblast cell lines, and hematopoietic cell lines rendering them growth factor independent[7,8,9,10]. Mouse models demonstrated that BCR-ABL expression in immature hematopoietic cells was sufficient to induce a CML-like syndrome in mice[11,12]. Other mouse models, including transgenic studies, were able to recapitulate at least some of the features of blast crisis[13,14,15,16]. These studies indicated that 
BCR-ABL expression in hematopoietic precursors was necessary and sufficient for the induction of leukemia.

Currently, the only known cure for CML is allogenic stem cell transplantation in the chronic phase of the disease. This therapy has demonstrated survival rates of $50-70 \%$ after 3-10 years of followup $[17,18,19]$. Unfortunately, this treatment is not an option for the majority of patients due to the lack of an HLA-matched related donor or the risk of transplantation-related mortality. Until recently, the standard treatment for patients unable to undergo allogenic stem cell transplantation was interferon-alpha (IFN- $\alpha$ ) alone or in combination with cytarabine[20,21]. While this therapy results in increased survival and a low rate of complete remission, it is associated with a range of adverse effects[22,23,24,25]. Due to the central role of BCR-ABL signaling in CML, investigators questioned whether direct pharmacologic inhibition of BCR-ABL could control the disease. In support of this approach, multiple mouse models of cancer, including a BCR-ABL-driven leukemia model, demonstrated that the initial oncogene, despite the presence of additional genetic hits, was required to maintain the tumor phenotype[16,26,27].

The 2-phenylamino pyrimidine inhibitor imatinib (CGP57148B, STI-571, Gleevec), developed by Novartis, was shown to inhibit a select group of kinases including c-Abl, c-Kit, Arg, and platelet-derived growth factor receptor (PDGF-R)[28,29,30]. Cocrystal studies of the Abl kinase domain with imatinib demonstrated that the inhibitor's specificity could be attributed to binding only the inactive form of the kinase by an induced-fit mechanism[31]. In preclinical models, imatinib inhibited cellular proliferation in BCR-ABL-expressing cells and tumor formation in animal models of CML[32]. In a phase I clinical trial, imatinib was shown to be well tolerated and have substantial activity against Ph-positive CML and ALL[6,33]. However, the clinical success of imatinib was limited early on, especially in blast crisis patients, by the development of resistance during the course of treatment[6]. Complete hematologic and cytogenetic responses were common and durable in chronic phase, but in blast crisis, where only a third of patients demonstrated sustained hematologic responses, the median duration of response was 10 months $[34,35,36]$. Despite this problem of drug resistance, imatinib has become front-line treatment for $\mathrm{Ph}$-positive leukemia patients who are not candidates for allogenic stem cell transplantation[23,37].

In addition to Ph-positive leukemia, imatinib was shown to be effective in treating gastrointestinal stromal tumor (GIST) and hypereosinophilic syndrome (HES) caused by activated forms of c-Kit and PDGF-R, respectively[38,39]. In the case of GIST, about half of the patients in a clinical trial achieved either a partial or complete response while on imatinib therapy[38]. However, acquired resistance to imatinib is well established in the literature for both of these malignancies[40,41].

\section{CLINICAL IMATINIB RESISTANCE IS PRIMARILY MEDIATED BY KINASE DOMAIN MUTATIONS}

Soon after the clinical introduction of imatinib, resistance to drug therapy was observed in patients due to kinase domain mutation preventing drug binding, or less frequently, by BCR-ABL genomic amplification[42]. The first reported clinical resistance BCR-ABL mutation at T315I (Abl type Ia sequencing numbering) was postulated to block imatinib from binding due to the loss of a drug-kinase hydrogen bond and a steric clash between imatinib and the bulky hydrocarbon isoleucine side chain in the mutant, meanwhile preserving ATP-binding and kinase activity[42]. Multiple subsequent studies have shown that kinase domain mutation is a major resistance mechanism in CML[37,43,44,45,46,47, $48,49,50,51]$. In a recent study of $84 \mathrm{Ph}$-positive leukemia patients resistant or intolerant to imatinib, $71 \%$ were shown to have BCR-ABL mutations[52]. Additional work demonstrated analogous resistance mutations in c-Kit and PDGF-R in the course of imatinib treatment of other malignancies[40,41]. Several of the CML studies demonstrated the presence of kinase domain mutations in patients never treated with imatinib, possibly indicating that at least some of these mutations confer increased biological fitness over wild-type BCR-ABL[47,53,54,55]. Mutations arising by chance that increase kinase fitness may allow for clonal expansion of one BCR-ABL mutant even in the absence of drug selection. The reported prevalence 
of resistance-conferring mutations in CML patients has ranged from $45-90 \%$ and represents the most significant mechanism of clinical resistance to therapy[37,44,52].

Following the report of the T315I mutation, other BCR-ABL mutations were uncovered in patients displaying varying degrees of drug resistance[42]. Comparison of the location of these resistance mutations to the cocrystal structure indicated that the majority of resistance mutations in clinical samples did not occur at drug contact residues[31]. Mutations at contact residues were observed including T315I, F317L, and F359V[44]. The remainder of the mutations occurred in the phosphate-binding loop (P-loop) including M244V, G250E, Q252H/R, Y253F/H, and E255K, near the activation loop, including M351T and $\mathrm{E} 355 \mathrm{G}$, and elsewhere in the molecule[44]. Those mutations that did not directly impair drug binding were postulated to prevent conformational changes in the P-loop and activation loop required for imatinib binding. Since imatinib only binds the inactive conformation of the kinase, any mutation that shifts the kinase to the active conformation or impinges on BCR-ABL autoinhibition will limit imatinib from binding[31,44].

This principle, first observed in clinical samples, was further supported by an in vitro mutagenesis study of BCR-ABL[56]. In a study by Azam et al., an unbiased genetic screen was performed to identify mutations that confer resistance to imatinib[56,57]. The screen recovered 112 amino acid substitutions at 90 residues[56]. Resistance mutations were recovered throughout BCR-ABL and, consistent with clinical observations, only a minority mapped to drug-kinase contact residues. This observation implies that inhibitors that bind alternate conformations of the kinase may have activity against many imatinibresistant BCR-ABL mutants.

Acquired resistance to small-molecule, inhibitor therapy mediated by kinase domain mutation is an emerging theme in targeted cancer therapy. Since the original T315I BCR-ABL mutation was described in CML, homologous mutations have been observed in other targeted kinases that mediate resistance[42]. Work from multiple labs has demonstrated acquired-resistance mutations in epidermal growth factor receptor (EGFR) in patients with non-small-cell lung cancer (NSCLC) treated with the EGFR inhibitors gefitinib (Iressa, AstraZeneca) and erlotinib (Tarceva, Genentech)[58,59]. The T790M EGFR mutation reported in NSCLC, conferring resistance to these compounds, is directly analogous to several acquired imatinib-resistant mutations in other kinases: the T674I PDGFR-alpha mutation in HES, the T670I KIT mutation in GIST, and the T315I BCR-ABL mutation first described in CML[40,41,42,59]. Additionally, one study indicated that the T790M EGFR mutation was present in a cell line that had never been treated with any of the EGFR inhibitors[59]. This further raises the possibility that some kinase domain mutations, in addition to mediating resistance, generate kinases of increased fitness.

\section{PROPOSED MECHANISMS OF RESISTANCE IN THE SETTING OF NONMUTANT BCR-ABL}

While BCR-ABL mutation and amplification likely contribute to nearly $90 \%$ of clinical imatinib resistance, alternate mechanisms of resistance have been proposed by investigators. One aim has been to identify mechanisms that prevent imatinib from reaching the target. Drug efflux, for example, has often been implicated in resistance to chemotherapeutics. In one study, investigators reported increases in the multidrug resistance (MDR1) gene that encodes the P-glycoprotein (Pgp) in a subclone of a resistant human leukemia line derived by growing the cells in increasing concentrations of imatinib[60]. Increased expression of Pgp could potentially deplete intracellular levels of imatinib, thereby reactivating BCRABL signaling. While some in vitro models have supported this finding, others have demonstrated that overexpression of Pgp in K562, a human CML cell line, does not confer resistance to imatinib[61,62,63]. These results may indicate that cell lines selected over time for imatinib resistance in vitro may not recapitulate actual mechanisms of resistance in patients. Other studies showed that imatinib may be sequestered in the plasma by drug-binding proteins. Plasma protein alpha1 acid glycoprotein (AGP) bound imatinib at physiologic concentrations in vitro and blocked the ability of imatinib to inhibit BCR- 
ABL kinase activity[64]. Whether drug efflux or plasma sequestration represent major mechanisms of resistance in CML still remains controversial.

Imatinib resistance might additionally result from loss of target dependence through the activation of alternate signaling pathways[65,66]. This possibility is supported by precedent that Src family kinases may operate downstream of BCR-ABL in CML[40,41,67,68]. This BCR-ABL-independent model of resistance relies on the activation of other tyrosine kinases to drive the disease. In an in vitro model of resistance, one group demonstrated that an imatinib-resistant K562 subline was sensitive to inhibition of the Src-family kinases Lyn and Hck, and that these kinases were up-regulated in patients who acquired resistance during the course of imatinib therapy[65]. The same group extended these observations to continuous cell lines derived from imatinib-resistant patients[66], but there is little current evidence that Src activation is responsible for true clinical resistance to imatinib in patients. If so, however, such patients may benefit from the current, dual SRC/ABL inhibitors in clinical development $[52,69,70]$. Future work will demonstrate the significance of BCR-ABL-independent pathway activation and whether inhibition of these pathways is a viable means of targeting imatinib-resistant CML. The proposed mechanisms of resistance to imatinib are summarized in Fig. 1.

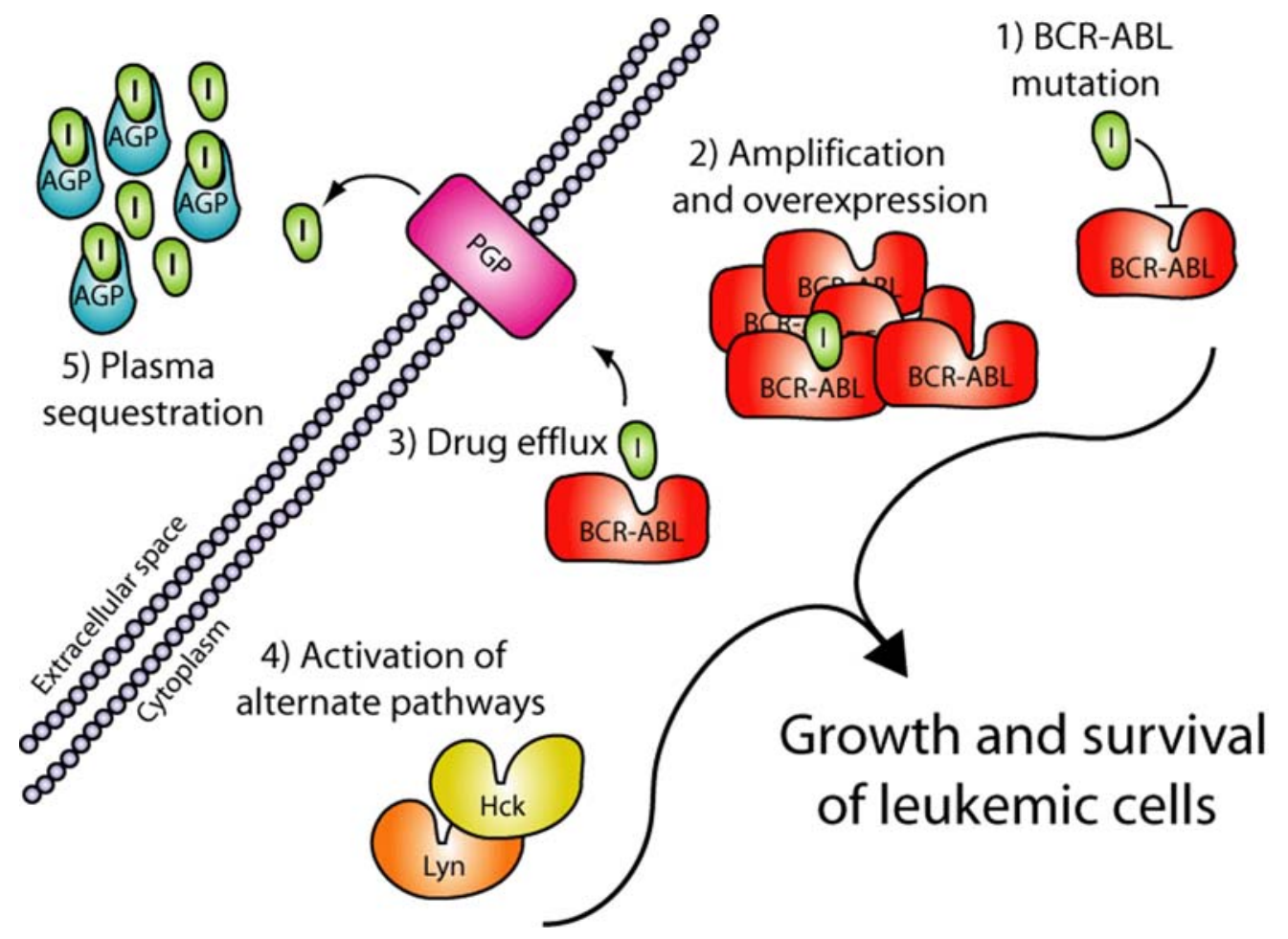

FIGURE 1. Mechanisms of imatinib resistance in CML. Clinical imatinib resistance is mediated primarily by (1) kinase domain mutation preventing imatinib from binding. (2) Genomic amplification and protein over expression of BCR-ABL has also been demonstrated in patients resistant to imatinib. Other mechanisms may include (3) drug efflux mediated by Pgp expression, (4) activation of alternate signaling pathways including the Src-family kinases Lyn and Hck, and (5) plasma sequestration by imatinib-binding proteins such as AGP. All mechanisms include the final common pathway of tyrosine kinase activity, promoting growth and survival of the leukemic cells. Imatinib is depicted as a green oval (I). 


\section{STRATEGIES FOR TARGETING IMATINIB-RESISTANT LEUKEMIA}

Clinical resistance to imatinib caused by mutation and reactivation of BCR-ABL signaling indicates that alternate therapies that continue to target the BCR-ABL protein should be effective. Multiple studies demonstrate that inhibition of BCR-ABL signaling by targeting protein stability, downstream signaling pathways, or by blocking kinase activity with structurally distinct inhibitors could be effective in imatinib resistance.

Targeting BCR-ABL stability should be an effective therapy when overexpression or mutation of BCR-ABL mediates resistance. BCR-ABL was shown to be a client of the molecular chaperone heat shock protein 90 (Hsp90)[71]. Hsp90 inhibition pharmacologically depleted cells of BCR-ABL protein and increased apoptosis. One study showed that inhibition of Hsp90 with geldanamycin and 17allylaminogeldanamycin (17-AAG, National Cancer Institute) could induce degradation of imatinibresistant, mutant BCR-ABL (T315I and E255K)[72]. Encouragingly, despite Hsp90 expression in normal tissue and in tumors, Hsp90 inhibitors may selectively kill cancer cells compared to normal cells because they have higher affinity for the activated conformation of Hsp90 found in malignant cells and therefore may be effective in patients[73]. Formulation and drug delivery issues have hampered the clinical evaluation of these drugs in CML.

Additional studies indicate that inhibition of histone deacetylases (HDAC) may block growth of leukemic cells by multiple mechanisms including decreasing BCR-ABL mRNA and protein levels. The HDAC inhibitor NVP-LAQ824 (Novartis) was shown to have activity against CML blast crisis cells[74]. Additional work demonstrated that HDAC inhibitors given in combination with imatinib may enhance the kinase inhibitor's cytotoxic effects[75,76]. Finally, recent studies using a combination of Hsp90 and HDAC inhibition have shown synergistic activity against both imatinib-sensitive and -resistant human leukemic cell lines driven by BCR-ABL[77].

Since BCR-ABL signaling is reactivated in imatinib resistance, targeting downstream pathways alone or in conjunction with BCR-ABL inhibition might control resistant disease. The Ras/MAPK pathway has been shown to be a critical effector pathway activated downstream of BCR-ABL[78,79,80]. Ras is a prototype, small, GTP-binding protein that when activated by receptor tyrosine kinases in a normal cellular context promotes cell cycle progression[81]. Genetic studies demonstrated that inactivation of Ras blocks BCR-ABL-induced transformation of fibroblasts and hematopoietic cells[82]. Farnesyl protein transferase inhibitors (FTIs) were originally designed to block mutant Ras signaling. However, FTIs also inhibit the growth of transformed cells with wild-type Ras, possibly due to effects on other farnesylated proteins. The FTI lonafarnib (SCH66336, Schering-Plough) was shown to inhibit proliferation in resistant cells and increase imatinib-driven apoptosis in sensitive cells[83]. In addition, lonafarnib was effective in reducing tumor burden in a p190 BCR-ABL mouse model of ALL[84]. These results indicate that FTIs may be effective in the setting of mutation or amplification of BCR-ABL. Other potential targets downstream of Ras include Raf-1 (BAY-439006, Onyx) and Mek (CI-1040, Pfizer), for which there are currently inhibitors in clinical development $[85,86]$.

Targeting the PI3K/Akt pathway downstream of BCR-ABL is another potential therapeutic strategy. Class Ia PI3K proteins are heterodimers consisting of a catalytic (p110) and regulatory (p85) subunit that convert phosphatidylinositol-4,5-bisphosphate to phosphatidylinositol-3,4,5-trisphosphate ( $\mathrm{PIP}_{3}$ ). Accumulation of $\mathrm{PIP}_{3}$ leads to activation of multiple downstream effectors including Akt and mTOR, promoting proliferation and survival[87]. Global inhibitors of the PI3K pathway, such as LY294002 (LY) and wortmannin, are able to block BCR-ABL-mediated transformation of hematopoietic cells[88]. Based on these studies, investigators have shown that it may be possible to target PI3K directly (with LY or wortmannin), Akt (with OSU-03012 [National Cancer Institute] that blocks Akt through PDK-1 inhibition), or downstream signals of Akt, such as mTOR (CCI-779, National Cancer Institute), to overcome imatinib resistance[89,90,92]. 


\section{TARGETING KINASE INHIBITOR RESISTANCE WITH ALTERNATE KINASE INHIBITORS}

Work from multiple investigators has shown that it is possible to overcome imatinib resistance by using BCR-ABL inhibitors that target the imatinib-resistant mutant forms of the kinase. A significantly more potent (10- to 50-fold) derivative of imatinib, nilotinib (Novartis), was recently shown to have a favorable safety profile in a Phase I trial of Ph-positive leukemia[93,94]. While nilotinib also binds the inactive form of the kinase, this compound is able to target all known imatinib-resistant mutants except T315I[94]. Mutations in the P-loop including L248R, Y253H, and E255K/V were less sensitive to nilotinib than wild-type BCR-ABL, but these mutants may be controlled in patients due to overall increased potency of nilotinib compared with imatinib[94].

Potent inhibitors of the Src-family tyrosine kinases are also able to inhibit BCR-ABL kinase activity[95]. While imatinib has not traditionally been considered an inhibitor of Src kinases, recent work has demonstrated that imatinib inhibits the Src-family tyrosine kinase Lck (and to a lesser degree Frk and Fyn), but not other Src-family members[96]. Structural studies demonstrated that the dual Src/Abl inhibitors, in contrast with imatinib, could bind BCR-ABL in an active conformation[31,97]. Since many of the imatinib-resistant mutants are postulated to prevent the kinase domain from achieving the closed conformation necessary for binding, inhibitors that target the active form of the kinase may be effective in these cases.

This principle was first demonstrated with the pyrido-pyrimidine class of dual Src/Abl inhibitors. Studies demonstrated that PD180970 and PD166326 (Pfizer) were effective in targeting most imatinibresistant forms of BCR-ABL except T315I[98,99,100]. Additional work indicated that PD166326 had greater antileukemic activity than imatinib in a mouse model of CML[101]. In the case of BCR-ABLindependent imatinib resistance, inhibition of the Src kinases with these compounds may be of additional therapeutic value[102].

Structurally distinct dual Src/Abl inhibitors have since been described. AP23464 (Ariad Pharmaceuticals Inc.), an ATP analog, was shown to be 200 -fold more potent than imatinib and able to target many imatinib-resistant forms of BCR-ABL except T315I[103]. Dasatinib (BMS-354825, BristolMyers Squibb), yet another dual Src/Abl inhibitor, was recently shown in a Phase I trial to induce hematologic and cytogenetic responses in patients with $\mathrm{Ph}$-positive leukemia resistant or intolerant to imatinib[52]. Dasatinib was shown to target most of the common imatinib-resistant forms of BCR-ABL except T315I[69,70]. The ability of dasatinib to inhibit almost all imatinib-resistant BCR-ABL mutants is likely due to conformation-tolerant binding. Recent cocrystal studies show that dasatinib recognizes multiple states of BCR-ABL[104,105]. Mutations that relieve BCR-ABL autoinhibition and shift the kinase to the imatinib-resistant, active conformation remain sensitive to dasatinib.

To date, all BCR-ABL kinase inhibitors that have been used clinically are not able to inhibit the T315I mutant. Recently, however, an allosteric BCR-ABL inhibitor was described that targets T315I and several other imatinib-resistant mutants[106]. The non-ATP competitive inhibitor, ON012380 (Onconova Therapeutics Inc.), targeted imatinib-resistant forms of BCR-ABL in cell lines and animal models in the low nanomolar range[106]. Additionally, recent work has shown that the Aurora kinase inhibitor VX-680 (Merck) and the p38 inhibitor BIRB-796 (Boehringer Ingelheim), two ATP-competitive compounds, are potential clinical T315I inhibitors[107]. While these results are encouraging, it remains to be determined whether these compounds will be tolerated in patients or have their own distinct set of resistance mutations, and highlights the need for clinical-grade inhibitors against T315I BCR-ABL.

Similarly, targeting mutant kinases with novel inhibitors is likely to be effective in other imatinibresistant malignancies. PKC412 (Novartis), an alternative inhibitor of PDGFR-alpha and Kit now in clinical trials for FLT3 driven acute myelogenous leukemia (AML), was shown to target the T674I mutation responsible for some clinical imatinib resistance in HES[108]. Additional work demonstrated that PKC412 could target some c-Kit and PDGFR-alpha mutants driving imatinib-resistant GIST[109,110]. Sunitinib (SU11248, Pfizer), a promiscuous compound that targets c-Kit, may also prove 
to be clinically useful in imatinib-resistant GIST[111]. Table 1 summarizes some of the compounds potentially useful in targeting imatinib-resistant malignancies.

TABLE 1

Summary of Compounds Utilized to Target Imatinib Resistance

\begin{tabular}{lccc}
\hline Mechanism of Action & Compound & Molecular Target(s) & Refs. \\
\hline BCR-ABL stability & Geldanamycin/17-AAG & HSP-90 & 72 \\
Downstream signaling & NVP-LAQ824 & Histone deacetylases & 74 \\
Ras/MAPK & lonafarnib (SCH66336) & Farnesyl protein transferase (Ras & 83,84 \\
& and other proteins) & \\
& BAY-439006 & Raf-1 & 85 \\
PI3K/Akt/mTOR & Cl-1040 & Mek & 86 \\
& LY294002/wortmanin & PI3K & 88 \\
BCR-ABL kinase activity & OSU-03012 & PDK-1 (Akt) & 89 \\
& CCI-779 & mTOR & 92 \\
& Nilotinib (AMN107) & BCR-ABL & 93,94 \\
& PD166326, PD180970 & BCR-ABL, Src kinases & $97,98,99,100,101$ \\
& AP23464 & BCR-ABL, Src kinases & 103 \\
& Dasatinib (BMS-354825) & BCR-ABL, Src kinases & 52 \\
ONO12380 & T315I BCR-ABL & 106 \\
Imatinib-resistant HES, & VX-680 & Aurora kinase, T315I BCR-ABL & 107 \\
GIST & BIRB-796 & p38, T315I BCR-ABL & 107 \\
& PKC412 & FLT3, PDGFR, VEGFR, PKC, C-Kit & $108,109,110$ \\
& Sunitinib (SU11248) & FLT3, PDGFR, VEGFR, C-Kit & 111 \\
\hline
\end{tabular}

\section{COMBINATION THERAPY}

Multiple studies have suggested that combination therapy of imatinib with conventional chemotherapeutics, drugs that decrease BCR-ABL stability, or inhibitors of downstream BCR-ABL targets could be more effective than imatinib alone[89,90,92,112,113,114,115,116]. Work from our laboratory has shown that imatinib in combination with other BCR-ABL kinase inhibitors that target distinct conformations of the kinase can limit the spectrum and emergence of resistant BCR-ABL clones in an in vitro assay and additively inhibit the growth of wild-type BCR-ABL-expressing cells[69]. In patients, treating BCR-ABL with multiple inhibitors could potentially delay the emergence of resistance and reduce disease burden due to the additive effect on wild-type BCR-ABL. Clinical trials that will assess the safety and efficacy of such a strategy seem warranted. While each of these compounds is likely to have its own distinct spectrum of mutations that confer resistance, a combination of three or more inhibitors all targeting BCR-ABL kinase activity may be of benefit in CML. This concept is supported by recent mathematical modeling of drug resistance in CML that predicts multiple non-cross-resistant drugs are needed to prevent treatment failure[117]. Additionally, due to the additive and possibly synergistic effects on wild-type BCR-ABL, such a cocktail is likely to be effective where genomic amplification of $B C R-A B L$ contributes to resistance. Imatinib is likely to remain a front-line CML therapy due to its safety 
and efficacy, but in the near future, we may see that a cocktail of BCR-ABL inhibitors, perhaps in combination with drugs that target downstream effectors, might delay resistance and more effectively control the disease.

\section{ACKNOWLEDGMENTS}

We thank Dr. Brian Skaggs for helpful discussions and critical reading of this manuscript. M.R.B. is supported by the NIH NIGMS training grant, GM08042, the Medical Scientist Training Program, and the Aesculapians Fund of the David Geffen School of Medicine at UCLA. C.L.S. is supported by grants from the Leukemia and Lymphoma Society, is an investigator of the Howard Hughes Medical Institute, and is a Doris Duke Distinguished Clinical Scientist.

\section{REFERENCES}

1. $\quad$ Sawyers, C.L. (1999) Chronic myeloid leukemia. N. Engl. J. Med. 340(17), 1330-1340.

2. Rowley, J.D. (1973) Letter: a new consistent chromosomal abnormality in chronic myelogenous leukaemia identified by quinacrine fluorescence and Giemsa staining. Nature 243(5405), 290-293.

3. Ben-Neriah, Y., Daley, G.Q., Mes-Masson, A.M., Witte, O.N., and Baltimore, D. (1986) The chronic myelogenous leukemia-specific P210 protein is the product of the bcr/abl hybrid gene. Science 233(4760), 212-214.

4. Konopka, J.B., Watanabe, S.M., and Witte, O.N. (1984) An alteration of the human c-abl protein in K562 leukemia cells unmasks associated tyrosine kinase activity. Cell 37(3), 1035-1042.

5. Kawasaki, E.S., Clark, S.S., Coyne, M.Y., Smith, S.D., Champlin, R., Witte,O.N., and McCormick, F.P. (1988) Diagnosis of chronic myeloid and acute lymphocytic leukemias by detection of leukemia-specific mRNA sequences amplified in vitro. Proc. Natl. Acad. Sci. U. S. A. 85(15), 5698-5702.

6. Druker, B.J., Sawyers, C.L., Kantarjian, H., Resta, D.J., Reese, S.F., Ford, J.M., Capdeville, R., and Talpaz, M. (2001) Activity of a specific inhibitor of the BCR-ABL tyrosine kinase in the blast crisis of chronic myeloid leukemia and acute lymphoblastic leukemia with the Philadelphia chromosome. N. Engl. J. Med. 344(14), 1038-1042.

7. Daley, G.Q. and Baltimore, D. (1988) Transformation of an interleukin 3-dependent hematopoietic cell line by the chronic myelogenous leukemia-specific P210bcr/abl protein. Proc. Natl. Acad. Sci. U. S. A. 85(23), 9312-9316.

8. McLaughlin, J., Chianese, E., and Witte, O.N. (1987) In vitro transformation of immature hematopoietic cells by the P210 BCR/ABL oncogene product of the Philadelphia chromosome. Proc. Natl. Acad. Sci. U. S. A. 84(18), 65586562.

9. Lugo, T.G. and Witte, O.N. (1989) The BCR-ABL oncogene transforms Rat-1 cells and cooperates with v-myc. Mol. Cell Biol. 9(3), 1263-1270.

10. Daley, G.Q., McLaughlin, J., Witte, O.N., and Baltimore, D. (1987) The CML-specific P210 bcr/abl protein, unlike vabl, does not transform NIH/3T3 fibroblasts. Science 237(4814), 532-535.

11. Kelliher, M.A., McLaughlin, J., Witte, O.N., and Rosenberg, N. (1990) Induction of a chronic myelogenous leukemia-like syndrome in mice with v-abl and BCR/ABL. Proc. Natl. Acad. Sci. U. S. A. 87(17), 6649-6653.

12. Daley, G.Q., Van Etten, R.A., and Baltimore, D. (1990) Induction of chronic myelogenous leukemia in mice by the P210bcr/abl gene of the Philadelphia chromosome. Science 247(4944), 824-830.

13. Daley, G.Q., Van Etten, R.A., and Baltimore, D. (1991) Blast crisis in a murine model of chronic myelogenous leukemia. Proc. Natl. Acad. Sci. U. S. A. 88(24), 11335-11338.

14. Heisterkamp, N., Jenster, G., ten Hoeve, J., Zovich, D., Pattengale, P.K., and Groffen, J. (1990) Acute leukaemia in bcr/abl transgenic mice. Nature 344(6263), 251-253.

15. Elefanty, A.G., Hariharan, I.K., and Cory, S. (1990) bcr-abl, the hallmark of chronic myeloid leukaemia in man, induces multiple haemopoietic neoplasms in mice. EMBO J. 9(4), 1069-1078.

16. Huettner, C.S., Zhang, P., Van Etten, R.A., and Tenen, D.G. (2000) Reversibility of acute B-cell leukaemia induced by BCR-ABL1. Nat. Genet. 24(1), 57-60.

17. Horowitz, M.M., Rowlings, P.A., and Passweg, J.R. (1996) Allogeneic bone marrow transplantation for CML: a report from the International Bone Marrow Transplant Registry. Bone Marrow Transplant. 17(Suppl 3), S5-6.

18. van Rhee, F., Szydlo, R.M., Hermans, J., Devergie, A., Frassoni, F., Arcese, W., de Witte, T., Kolb, H.J., Niederwiser, D., Jacobsen, N., et al. (1997) Long-term results after allogeneic bone marrow transplantation for chronic myelogenous leukemia in chronic phase: a report from the Chronic Leukemia Working Party of the European Group for Blood and Marrow Transplantation. Bone Marrow Transplant. 20(7), 553-560.

19. Clift, R.A. and Anasetti, C. (1997) Allografting for chronic myeloid leukaemia. Baillieres Clin. Haematol. 10(2), 319-336.

20. Kantarjian, H.M., O'Brien, S., Smith, T.L., Rios, M.B., Cortes, J., Beran, M., Koller, C., Giles, F.J., Andreeff, M., 
Kornblau, S., et al. (1999) Treatment of Philadelphia chromosome-positive early chronic phase chronic myelogenous leukemia with daily doses of interferon alpha and low-dose cytarabine. J. Clin. Oncol. 17(1), 284-292.

21. Hehlmann, R., Heimpel, H., Hasford, J., Kolb, H.J., Pralle, H., Hossfeld, D.K., Queisser, W., Loffler, H., Hochhaus, A., Heinze, B., et al. (1994) Randomized comparison of interferon-alpha with busulfan and hydroxyurea in chronic myelogenous leukemia. The German CML Study Group. Blood 84(12), 4064-4077.

22. Silver, R.T., Woolf, S.H., Hehlmann, R., Appelbaum, F.R., Anderson, J., Bennett, C., Goldman, J.M., Guilhot, F., Kantarjian, H.M., Lichtin, A.E., et al. (1999) An evidence-based analysis of the effect of busulfan, hydroxyurea, interferon, and allogeneic bone marrow transplantation in treating the chronic phase of chronic myeloid leukemia: developed for the American Society of Hematology. Blood 94(5), 1517-1536.

23. Anstrom, K.J., Reed, S.D., Allen, A.S., Glendenning, G.A., and Schulman, K.A. (2004) Long-term survival estimates for imatinib versus interferon-alpha plus low-dose cytarabine for patients with newly diagnosed chronic-phase chronic myeloid leukemia. Cancer 101(11), 2584-2592.

24. Hahn, E.A., Glendenning, G.A., Sorensen, M.V., Hudgens, S.A., Druker, B.J., Guilhot, F., Larson, R.A., O'Brien, S.G., Dobrez, D.G., Hensley, M.L., et al. (2003) Quality of life in patients with newly diagnosed chronic phase chronic myeloid leukemia on imatinib versus interferon alfa plus low-dose cytarabine: results from the IRIS Study. $J$. Clin. Oncol. 21(11), 2138-2146.

25. Bonifazi, F., de Vivo, A., Rosti, G., Guilhot, F., Guilhot, J., Trabacchi, E., Hehlmann, R., Hochhaus, A., Shepherd, P.C., Steegmann, J.L., et al. (2001) Chronic myeloid leukemia and interferon-alpha: a study of complete cytogenetic responders. Blood 98(10), 3074-3081.

26. Felsher, D.W. and Bishop, J.M. (1999) Reversible tumorigenesis by MYC in hematopoietic lineages. Mol. Cell 4(2), 199-207.

27. Chin, L., Tam, A., Pomerantz, J., Wong, M., Holash, J., Bardeesy, N., Shen, Q., O'Hagan, R., Pantginis, J., Zhou, H., et al. (1999) Essential role for oncogenic Ras in tumour maintenance. Nature 400(6743), 468-472.

28. Okuda, K., Weisberg, E., Gilliland, D.G., and Griffin, J.D. (2001) ARG tyrosine kinase activity is inhibited by STI571. Blood 97(8), 2440-2448.

29. Buchdunger, E., Cioffi, C.L., Law, N., Stover, D., Ohno-Jones, S., Druker, B.J., and Lydon, N.B. (2000) Abl proteintyrosine kinase inhibitor STI571 inhibits in vitro signal transduction mediated by c-kit and platelet-derived growth factor receptors. J. Pharmacol. Exp. Ther. 295(1), 139-145.

30. Buchdunger, E., Zimmermann, J., Mett, H., Meyer, T., Muller, M., Druker, B.J., and Lydon, N.B. (1996) Inhibition of the Abl protein-tyrosine kinase in vitro and in vivo by a 2-phenylaminopyrimidine derivative. Cancer Res. 56(1), $100-104$.

31. Schindler, T., Bornmann, W., Pellicena, P., Miller, W.T., Clarkson, B., and Kuriyan, J. (2000) Structural mechanism for STI-571 inhibition of abelson tyrosine kinase. Science 289(5486), 1938-1942.

32. Druker, B.J., Tamura, S., Buchdunger, E., Ohno, S., Segal, G.M., Fanning, S., Zimmermann, J., and Lydon, N.B. (1996) Effects of a selective inhibitor of the Abl tyrosine kinase on the growth of Bcr-Abl positive cells. Nat. Med. 2(5), 561-566.

33. Druker, B.J., Talpaz, M., Resta, D.J., Peng, B., Buchdunger, E., Ford, J.M., Lydon, N.B., Kantarjian, H., Capdeville, R., Ohno-Jones, S., et al. (2001) Efficacy and safety of a specific inhibitor of the BCR-ABL tyrosine kinase in chronic myeloid leukemia. N. Engl. J. Med. 344(14), 1031-1037.

34. Kantarjian, H., Sawyers, C., Hochhaus, A., Guilhot, F., Schiffer, C., Gambacorti-Passerini, C., Niederwieser, D., Resta, D., Capdeville, R., Zoellner, U., et al. (2002) Hematologic and cytogenetic responses to imatinib mesylate in chronic myelogenous leukemia. N. Engl. J. Med. 346(9), 645-652.

35. Ottmann, O.G., Druker, B.J., Sawyers, C.L., Goldman, J.M., Reiffers, J., Silver, R.T., Tura, S., Fischer, T., Deininger, M.W., Schiffer, C.A., et al. (2002) A phase 2 study of imatinib in patients with relapsed or refractory Philadelphia chromosome-positive acute lymphoid leukemias. Blood 100(6), 1965-1971.

36. Sawyers, C.L., Hochhaus, A., Feldman, E., Goldman, J.M., Miller, C.B., Ottmann, O.G., Schiffer, C.A., Talpaz, M., Guilhot, F., Deininger, M.W., et al. (2002) Imatinib induces hematologic and cytogenetic responses in patients with chronic myelogenous leukemia in myeloid blast crisis: results of a phase II study. Blood 99(10), 3530-3539.

37. Lahaye, T., Riehm, B., Berger, U., Paschka, P., Muller, M.C., Kreil, S., Merx, K., Schwindel, U., Schoch, C., Hehlmann, R., et al. (2005) Response and resistance in 300 patients with BCR-ABL-positive leukemias treated with imatinib in a single center. Cancer 103(8), 1659-1669.

38. Verweij, J., Casali, P.G., Zalcberg, J., LeCesne, A., Reichardt, P., Blay, J.Y., Issels, R., van Oosterom, A., Hogendoorn, P.C., Van Glabbeke, M., et al. (2004) Progression-free survival in gastrointestinal stromal tumours with high-dose imatinib: randomised trial. Lancet 364(9440), 1127-1134.

39. Cortes, J., Ault, P., Koller, C., Thomas, D., Ferrajoli, A., Wierda, W., Rios, M.B., Letvak, L., Kaled, E.S., and Kantarjian, H. (2003) Efficacy of imatinib mesylate in the treatment of idiopathic hypereosinophilic syndrome. Blood 101(12), 4714-4716.

40. Tamborini, E., Bonadiman, L., Greco, A., Albertini, V., Negri, T., Gronchi, A., Bertulli, R., Colecchia, M., Casali, P.G., Pierotti, M.A., et al. (2004) A new mutation in the KIT ATP pocket causes acquired resistance to imatinib in a gastrointestinal stromal tumor patient. Gastroenterology 127(1), 294-299.

41. Cools, J., DeAngelo, D.J., Gotlib, J., Stover, E.H., Legare, R.D., Cortes, J., Kutok, J., Clark, J., Galinsky, I., Griffin, J.D., et al. (2003) A tyrosine kinase created by fusion of the PDGFRA and FIP1L1 genes as a therapeutic target of 
imatinib in idiopathic hypereosinophilic syndrome. N. Engl. J. Med. 348(13), 1201-1214.

42. Gorre, M.E., Mohammed, M., Ellwood, K., Hsu, N., Paquette, R., Rao, P.N., and Sawyers, C.L. (2001) Clinical resistance to STI-571 cancer therapy caused by BCR-ABL gene mutation or amplification. Science 293(5531), 876880.

43. Hofmann, W.K., Jones, L.C., Lemp, N.A., de Vos, S., Gschaidmeier, H., Hoelzer, D., Ottmann, O.G., and Koeffler, H.P. (2002) $\mathrm{Ph}(+)$ acute lymphoblastic leukemia resistant to the tyrosine kinase inhibitor STI571 has a unique BCRABL gene mutation. Blood 99(5), 1860-1862.

44. Shah, N.P., Nicoll, J.M., Nagar, B., Gorre, M.E., Paquette, R.L., Kuriyan, J., and Sawyers, C.L. (2002) Multiple BCR-ABL kinase domain mutations confer polyclonal resistance to the tyrosine kinase inhibitor imatinib (STI571) in chronic phase and blast crisis chronic myeloid leukemia. Cancer Cell 2(2), 117-125.

45. Roumiantsev, S., Shah, N.P., Gorre, M.E., Nicoll, J., Brasher, B.B., Sawyers, C.L., and Van Etten, R.A. (2002) Clinical resistance to the kinase inhibitor STI-571 in chronic myeloid leukemia by mutation of Tyr-253 in the Abl kinase domain P-loop. Proc. Natl. Acad. Sci. U. S. A. 99(16), 10700-10705.

46. Muller, M.C., Lahaye, T., and Hochhaus, A. (2002) [Resistance to tumor specific therapy with imatinib by clonal selection of mutated cells]. Dtsch. Med. Wochenschr. 127(42), 2205-2207.

47. Hofmann, W.K., Komor, M., Wassmann, B., Jones, L.C., Gschaidmeier, H., Hoelzer, D., Koeffler, H.P., and Ottmann, O.G. (2003) Presence of the BCR-ABL mutation Glu255Lys prior to STI571 (imatinib) treatment in patients with $\mathrm{Ph}+$ acute lymphoblastic leukemia. Blood 102(2), 659-661.

48. Corbin, A.S., La Rosee, P., Stoffregen, E.P., Druker, B.J., and Deininger, M.W. (2003) Several Bcr-Abl kinase domain mutants associated with imatinib mesylate resistance remain sensitive to imatinib. Blood 101(11), 4611-4614. Branford, S., Rudzki, Z., Walsh, S., Grigg, A., Arthur, C., Taylor, K., Herrmann, R., Lynch, K.P., and Hughes, T.P. (2002) High frequency of point mutations clustered within the adenosine triphosphate-binding region of BCR/ABL in patients with chronic myeloid leukemia or Ph-positive acute lymphoblastic leukemia who develop imatinib (STI571) resistance. Blood 99(9), 3472-3475.

50. Al-Ali, H.K., Heinrich, M.C., Lange, T., Krahl, R., Mueller, M., Muller, C., Niederwieser, D., Druker, B.J., and Deininger, M.W. (2004) High incidence of BCR-ABL kinase domain mutations and absence of mutations of the PDGFR and KIT activation loops in CML patients with secondary resistance to imatinib. Hematol. J. 5(1), 55-60.

51. Hato, T., Yamanouchi, J., Tamura, T., Hojo, N., Niiya, Y., Kohno, M., Bando, S., Yakushijin, Y., Takada, K., Sakai, I., et al. (2004) Existence of leukemic clones resistant to both imatinib mesylate and rituximab before drug therapies in a patient with Philadelphia chromosome-positive acute lymphocytic leukemia. Int. J. Hematol. 80(1), 62-66.

52. Talpaz, M., Shah, N.P., Kantarjian, H., Donato, N., Nicoll, J., Paquette, R., Cortes, J., O'Brien, S., Nicaise, C., Bleickardt, E., et al. (2006) Dasatinib in imatinib-resistant Philadelphia chromosome-positive leukemias. N. Engl. J. Med. 354(24), 2531-2541.

53. Roche-Lestienne, C., Soenen-Cornu, V., Grardel-Duflos, N., Lai, J.L., Philippe, N., Facon, T., Fenaux, P., and Preudhomme, C. (2002) Several types of mutations of the Abl gene can be found in chronic myeloid leukemia patients resistant to STI571, and they can pre-exist to the onset of treatment. Blood 100(3), 1014-1018.

54. Roche-Lestienne, C. and Preudhomme, C. (2003) Mutations in the ABL kinase domain pre-exist the onset of imatinib treatment. Semin. Hematol. 40(2 Suppl 2), 80-82.

55. Roche-Lestienne, C., Lai, J.L., Darre, S., Facon, T., and Preudhomme, C. (2003) A mutation conferring resistance to imatinib at the time of diagnosis of chronic myelogenous leukemia. N. Engl. J. Med. 348(22), 2265-2266.

56. Azam, M., Latek, R.R., and Daley, G.Q. (2003) Mechanisms of autoinhibition and STI-571/imatinib resistance revealed by mutagenesis of BCR-ABL. Cell 112(6), 831-843.

57. Azam, M., Raz, T., Nardi, V., Opitz, S.L., and Daley, G.Q. (2003) A screen to identify drug resistant variants to target-directed anti-cancer agents. Biol. Proced. Online 5, 204-210.

58. Kobayashi, S., Boggon, T.J., Dayaram, T., Janne, P.A., Kocher, O., Meyerson, M., Johnson, B.E., Eck, M.J., Tenen, D.G., and Halmos, B. (2005) EGFR mutation and resistance of non-small-cell lung cancer to gefitinib. N. Engl. J. Med. 352(8), 786-792.

59. Pao, W., Miller, V.A., Politi, K.A., Riely, G.J., Somwar, R., Zakowski, M.F., Kris, M.G., and Varmus, H. (2005) Acquired resistance of lung adenocarcinomas to gefitinib or erlotinib is associated with a second mutation in the EGFR kinase domain. PLoS Med. 2(3), e73.

60. Mahon, F.X., Deininger, M.W., Schultheis, B., Chabrol, J., Reiffers, J., Goldman, J.M., and Melo, J.V. (2000) Selection and characterization of BCR-ABL positive cell lines with differential sensitivity to the tyrosine kinase inhibitor STI571: diverse mechanisms of resistance. Blood 96(3), 1070-1079.

61. Illmer, T., Schaich, M., Platzbecker, U., Freiberg-Richter, J., Oelschlagel, U., von Bonin, M., Pursche, S., Bergemann, T., Ehninger, G., and Schleyer, E. (2004) P-glycoprotein-mediated drug efflux is a resistance mechanism of chronic myelogenous leukemia cells to treatment with imatinib mesylate. Leukemia 18(3), 401-408.

62. Mahon, F.X., Belloc, F., Lagarde, V., Chollet, C., Moreau-Gaudry, F., Reiffers, J., Goldman, J.M., and Melo, J.V. (2003) MDR1 gene overexpression confers resistance to imatinib mesylate in leukemia cell line models. Blood 101(6), 2368-2373.

63. Ferrao, P.T., Frost, M.J., Siah, S.P., and Ashman, L.K. (2003) Overexpression of P-glycoprotein in K562 cells does not confer resistance to the growth inhibitory effects of imatinib (STI571) in vitro. Blood 102(13), 4499-4503.

64. Gambacorti-Passerini, C., Barni, R., le Coutre, P., Zucchetti, M., Cabrita, G., Cleris, L., Rossi, F., Gianazza, E., 
Brueggen, J., Cozens, R., et al. (2000) Role of alpha1 acid glycoprotein in the in vivo resistance of human BCRABL (+) leukemic cells to the abl inhibitor STI571. J. Natl. Cancer Inst. 92(20), 1641-1650.

65. Donato, N.J., Wu, J.Y., Stapley, J., Gallick, G., Lin, H., Arlinghaus, R., and Talpaz, M. (2003) BCR-ABL independence and LYN kinase overexpression in chronic myelogenous leukemia cells selected for resistance to STI571. Blood 101(2), 690-698.

66. Donato, N.J., Wu, J.Y., Stapley, J., Lin, H., Arlinghaus, R., Aggarwal, B.B., Shishodia, S., Albitar, M., Hayes, K., Kantarjian, H., et al. (2004) Imatinib mesylate resistance through BCR-ABL independence in chronic myelogenous leukemia. Cancer Res. 64(2), 672-677.

67. Lionberger, J.M., Wilson, M.B., and Smithgall, T.E. (2000) Transformation of myeloid leukemia cells to cytokine independence by Bcr-Abl is suppressed by kinase-defective Hck. J. Biol. Chem. 275(24), 18581-18585.

68. Roginskaya, V., Zuo, S., Caudell, E., Nambudiri, G., Kraker, A.J., and Corey, S.J. (1999) Therapeutic targeting of Src-kinase Lyn in myeloid leukemic cell growth. Leukemia 13(6), 855-861.

69. Burgess, M.R., Skaggs, B.J., Shah, N.P., Lee, F.Y., and Sawyers, C.L. (2005) Comparative analysis of two clinically active BCR-ABL kinase inhibitors reveals the role of conformation-specific binding in resistance. Proc. Natl. Acad. Sci. U. S. A. 102(9), 3395-3400.

70. Shah, N.P., Tran, C., Lee, F.Y., Chen, P., Norris, D., and Sawyers, C.L. (2004) Overriding imatinib resistance with a novel ABL kinase inhibitor. Science 305(5682), 399-401.

71. Blagosklonny, M.V., Fojo, T., Bhalla, K.N., Kim, J.S., Trepel, J.B., Figg, W.D., Rivera, Y., and Neckers, L.M. (2001) The Hsp90 inhibitor geldanamycin selectively sensitizes Bcr-Abl-expressing leukemia cells to cytotoxic chemotherapy. Leukemia 15(10), 1537-1543.

72. Gorre, M.E., Ellwood-Yen, K., Chiosis, G., Rosen, N., and Sawyers, C.L. (2002) BCR-ABL point mutants isolated from patients with imatinib mesylate-resistant chronic myeloid leukemia remain sensitive to inhibitors of the BCRABL chaperone heat shock protein 90. Blood 100(8), 3041-3044.

73. Kamal, A., Thao, L., Sensintaffar, J., Zhang, L., Boehm, M.F., Fritz, L.C., and Burrows, F.J. (2003) A high-affinity conformation of Hsp90 confers tumour selectivity on Hsp90 inhibitors. Nature 425(6956), 407-410.

74. Nimmanapalli, R., Fuino, L., Bali, P., Gasparetto, M., Glozak, M., Tao, J., Moscinski, L., Smith, C., Wu, J., Jove, R., et al. (2003) Histone deacetylase inhibitor LAQ824 both lowers expression and promotes proteasomal degradation of $\mathrm{Bcr}-\mathrm{Abl}$ and induces apoptosis of imatinib mesylate-sensitive or -refractory chronic myelogenous leukemia-blast crisis cells. Cancer Res. 63(16), 5126-5135.

75. Nimmanapalli, R., Fuino, L., Stobaugh, C., Richon, V., and Bhalla, K. (2003) Cotreatment with the histone deacetylase inhibitor suberoylanilide hydroxamic acid (SAHA) enhances imatinib-induced apoptosis of Bcr-Ablpositive human acute leukemia cells. Blood 101(8), 3236-3239.

76. Weisberg, E., Catley, L., Kujawa, J., Atadja, P., Remiszewski, S., Fuerst, P., Cavazza, C., Anderson, K., and Griffin, J.D. (2004) Histone deacetylase inhibitor NVP-LAQ824 has significant activity against myeloid leukemia cells in vitro and in vivo. Leukemia 18(12), 1951-1963.

77. Rahmani, M., Reese, E., Dai, Y., Bauer, C., Kramer, L.B., Huang, M., Jove, R., Dent, P., and Grant, S. (2005) Cotreatment with suberanoylanilide hydroxamic acid and 17-allylamino 17-demethoxygeldanamycin synergistically induces apoptosis in Bcr-Abl+ cells sensitive and resistant to STI571 (imatinib mesylate) in association with downregulation of Bcr-Abl, abrogation of signal transducer and activator of transcription 5 activity, and Bax conformational change. Mol. Pharmacol. 67(4), 1166-1176.

78. Skorski, T., Kanakaraj, P., Ku, D.H., Nieborowska-Skorska, M., Canaani, E., Zon, G., Perussia, B., and Calabretta, B. (1994) Negative regulation of p120GAP GTPase promoting activity by p210bcr/abl: implication for RAS-dependent Philadelphia chromosome positive cell growth. J. Exp. Med. 179(6), 1855-1865.

79. Mandanas, R.A., Leibowitz, D.S., Gharehbaghi, K., Tauchi, T., Burgess, G.S., Miyazawa, K., Jayaram, H.N., and Boswell, H.S. (1993) Role of p21 RAS in p210 bcr-abl transformation of murine myeloid cells. Blood 82(6), 18381847.

80. Pendergast, A.M., Quilliam, L.A., Cripe, L.D., Bassing, C.H., Dai, Z., Li, N., Batzer, A., Rabun, K.M., Der, C.J., Schlessinger, J., et al. (1993) BCR-ABL-induced oncogenesis is mediated by direct interaction with the SH2 domain of the GRB-2 adaptor protein. Cell 75(1), 175-185.

81. Coleman, M.L., Marshall, C.J., and Olson, M.F. (2004) RAS and RHO GTPases in G1-phase cell-cycle regulation. Nat. Rev. Mol. Cell Biol. 5(5), 355-366.

82. Sawyers, C.L., McLaughlin, J., and Witte, O.N. (1995) Genetic requirement for Ras in the transformation of fibroblasts and hematopoietic cells by the Bcr-Abl oncogene. J. Exp. Med. 181(1), 307-313.

83. Hoover, R.R., Mahon, F.X., Melo, J.V., and Daley, G.Q. (2002) Overcoming STI571 resistance with the farnesyl transferase inhibitor SCH66336. Blood 100(3), 1068-1071.

84. Mishra, S., Zhang, B., Groffen, J., and Heisterkamp, N. (2004) A farnesyltransferase inhibitor increases survival of mice with very advanced stage acute lymphoblastic leukemia/lymphoma caused by P190 Bcr/Abl. Leukemia 18(1), 23-28.

85. Lyons, J.F., Wilhelm, S., Hibner, B., and Bollag, G. (2001) Discovery of a novel Raf kinase inhibitor. Endocr. Relat. Cancer 8(3), 219-225.

86. Rinehart, J., Adjei, A.A., Lorusso, P.M., Waterhouse, D., Hecht, J.R., Natale, R.B., Hamid, O., Varterasian, M., Asbury, P., Kaldjian, E.P., et al. (2004) Multicenter phase II study of the oral MEK inhibitor, CI-1040, in patients 
with advanced non-small-cell lung, breast, colon, and pancreatic cancer. J. Clin. Oncol. 22(22), 4456-4462.

87. Vivanco, I. and Sawyers, C.L. (2002) The phosphatidylinositol 3-kinase AKT pathway in human cancer. Nat. Rev. Cancer 2(7), 489-501.

88. Skorski, T., Bellacosa, A., Nieborowska-Skorska, M., Majewski, M., Martinez, R., Choi, J.K., Trotta, R., Wlodarski, P., Perrotti, D., Chan, T.O., et al. (1997) Transformation of hematopoietic cells by BCR/ABL requires activation of a PI-3k/Akt-dependent pathway. EMBO J. 16(20), 6151-6161.

89. Tseng, P.H., Lin, H.P., Zhu, J., Chen, K.F., Hade, E.M., Young, D.C., Byrd, J.C., Grever, M., Johnson, K., Druker, B.J., et al. (2005) Synergistic interactions between imatinib and the novel phosphoinositide-dependent kinase-1 inhibitor OSU-03012 in overcoming imatinib resistance. Blood 105(10), 4021-4027.

90. Klejman, A., Rushen, L., Morrione, A., Slupianek, A., and Skorski, T. (2002) Phosphatidylinositol-3 kinase inhibitors enhance the anti-leukemia effect of STI571. Oncogene 21(38), 5868-5876.

91. Parmar, S., Smith, J., Sassano, A., Uddin, S., Katsoulidis, E., Majchrzak, B., Kambhampati, S., Eklund, E.A., Tallman, M.S., Fish, E.N., et al. (2005) Differential regulation of the p70 S6 kinase pathway by interferon \{alpha\} and imatinib mesylate (STI571) in chronic myelogenous leukemia cells. Blood 106(7), 2436-2443.

92. Mohi, M.G., Boulton, C., Gu, T.L., Sternberg, D.W., Neuberg, D., Griffin, J.D., Gilliland, D.G., and Neel, B.G. (2004) Combination of rapamycin and protein tyrosine kinase (PTK) inhibitors for the treatment of leukemias caused by oncogenic PTKs. Proc. Natl. Acad. Sci. U. S. A. 101(9), 3130-3135.

93. Kantarjian, H., Giles, F., Wunderle, L., Bhalla, K., O'Brien, S., Wassmann, B., Tanaka, C., Manley, P., Rae, P., Mietlowski, W., et al. (2006) Nilotinib in imatinib-resistant CML and Philadelphia chromosome-positive ALL. $N$. Engl. J. Med. 354(24), 2542-2551.

94. Weisberg, E., Manley, P.W., Breitenstein, W., Bruggen, J., Cowan-Jacob, S.W., Ray, A., Huntly, B., Fabbro, D., Fendrich, G., Hall-Meyers, E., et al. (2005) Characterization of AMN107, a selective inhibitor of native and mutant Bcr-Abl. Cancer Cell 7(2), 129-141.

95. Dorsey, J.F., Jove, R., Kraker, A.J., and Wu, J. (2000) The pyrido[2,3-d]pyrimidine derivative PD180970 inhibits p210Bcr-Abl tyrosine kinase and induces apoptosis of K562 leukemic cells. Cancer Res. 60(12), 3127-3131.

96. Fabian, M.A., Biggs, W.H., 3rd, Treiber, D.K., Atteridge, C.E., Azimioara, M.D., Benedetti, M.G., Carter, T.A., Ciceri, P., Edeen, P.T., Floyd, M., et al. (2005) A small molecule-kinase interaction map for clinical kinase inhibitors. Nat. Biotechnol. 23(3), 329-336.

97. Nagar, B., Bornmann, W.G., Pellicena, P., Schindler, T., Veach, D.R., Miller, W.T., Clarkson, B., and Kuriyan, J. (2002) Crystal structures of the kinase domain of c-Abl in complex with the small molecule inhibitors PD173955 and imatinib (STI-571). Cancer Res. 62(15), 4236-4243.

98. La Rosee, P., Corbin, A.S., Stoffregen, E.P., Deininger, M.W., and Druker, B.J. (2002) Activity of the Bcr-Abl kinase inhibitor PD180970 against clinically relevant Bcr-Abl isoforms that cause resistance to imatinib mesylate (Gleevec, STI571). Cancer Res. 62(24), 7149-7153.

99. Huron, D.R., Gorre, M.E., Kraker, A.J., Sawyers, C.L., Rosen, N., and Moasser, M.M. (2003) A novel pyridopyrimidine inhibitor of abl kinase is a picomolar inhibitor of Bcr-abl-driven K562 cells and is effective against STI571-resistant Bcr-abl mutants. Clin. Cancer Res. 9(4), 1267-1273.

100. von Bubnoff, N., Veach, D.R., Miller, W.T., Li, W., Sanger, J., Peschel, C., Bornmann, W.G., Clarkson, B., and Duyster, J. (2003) Inhibition of wild-type and mutant Bcr-Abl by pyrido-pyrimidine-type small molecule kinase inhibitors. Cancer Res. 63(19), 6395-6404.

101. Wolff, N.C., Veach, D.R., Tong, W.P., Bornmann, W.G., Clarkson, B., and Ilaria, R.L. (2005) PD166326, a novel tyrosine kinase inhibitor, has greater anti-leukemic activity than imatinib in a murine model of chronic myeloid leukemia. Blood 105(10), 3995-4003.

102. Dai, Y., Rahmani, M., Corey, S.J., Dent, P., and Grant, S. (2004) A Bcr/Abl-independent, Lyn-dependent form of imatinib mesylate (STI-571) resistance is associated with altered expression of Bcl-2. J. Biol. Chem. 279(33), 3422734239.

103. O'Hare, T., Pollock, R., Stoffregen, E.P., Keats, J.A., Abdullah, O.M., Moseson, E.M., Rivera, V.M., Tang, H., Metcalf, C.A., 3rd, Bohacek, R.S., et al. (2004) Inhibition of wild-type and mutant Bcr-Abl by AP23464, a potent ATP-based oncogenic protein kinase inhibitor: implications for CML. Blood 104(8), 2532-2539.

104. Tokarski, J.S., Newitt, J.A., Chang, C.Y., Cheng, J.D., Wittekind, M., Kiefer, S.E., Kish, K., Lee, F.Y., Borzillerri, R., Lombardo, L.J., et al. (2006) The structure of Dasatinib (BMS-354825) bound to activated ABL kinase domain elucidates its inhibitory activity against imatinib-resistant ABL mutants. Cancer Res. 66(11), 5790-5797.

105. Lombardo, L.J., Lee, F.Y., Chen, P., Norris, D., Barrish, J.C., Behnia, K., Castaneda, S., Cornelius, L.A., Das, J., Doweyko, A.M., et al. (2004) Discovery of N-(2-chloro-6-methyl- phenyl)-2-(6-(4-(2-hydroxyethyl)- piperazin-1-yl)2-methylpyrimidin-4- ylamino)thiazole-5-carboxamide (BMS-354825), a dual Src/Abl kinase inhibitor with potent antitumor activity in preclinical assays. J. Med. Chem. 47(27), 6658-6661.

106. Gumireddy, K., Baker, S.J., Cosenza, S.C., John, P., Kang, A.D., Robell, K.A., Reddy, M.V., and Reddy, E.P. (2005) A non-ATP-competitive inhibitor of BCR-ABL overrides imatinib resistance. Proc. Natl. Acad. Sci. U. S. A. 102(6), 1992-1997.

107. Carter, T.A., Wodicka, L.M., Shah, N.P., Velasco, A.M., Fabian, M.A., Treiber, D.K., Milanov, Z.V., Atteridge, C.E., Biggs, W.H., 3rd, Edeen, P.T., et al. (2005) Inhibition of drug-resistant mutants of ABL, KIT, and EGF receptor kinases. Proc. Natl. Acad. Sci. U. S. A. 102(31), 11011-11016. 
108. Cools, J., Stover, E.H., Boulton, C.L., Gotlib, J., Legare, R.D., Amaral, S.M., Curley, D.P., Duclos, N., Rowan, R., Kutok, J.L., et al. (2003) PKC412 overcomes resistance to imatinib in a murine model of FIP1L1-PDGFRalphainduced myeloproliferative disease. Cancer Cell 3(5), 459-469.

109. Growney, J.D., Clark, J.J., Adelsperger, J., Stone, R., Fabbro, D., Griffin, J.D., and Gilliland, D.G. (2005) Activation mutations of human c-KIT resistant to imatinib are sensitive to the tyrosine kinase inhibitor PKC412. Blood 106(2), 721-724..

110. Debiec-Rychter, M., Cools, J., Dumez, H., Sciot, R., Stul, M., Mentens, N., Vranckx, H., Wasag, B., Prenen, H., Roesel, J., et al. (2005) Mechanisms of resistance to imatinib mesylate in gastrointestinal stromal tumors and activity of the PKC412 inhibitor against imatinib-resistant mutants. Gastroenterology 128(2), 270-279.

111. Abrams, T.J., Lee, L.B., Murray, L.J., Pryer, N.K., and Cherrington, J.M. (2003) SU11248 inhibits KIT and plateletderived growth factor receptor beta in preclinical models of human small cell lung cancer. Mol. Cancer Ther. 2(5), 471-478.

112. La Rosee, P., Johnson, K., O'Dwyer, M.E., and Druker, B.J. (2002) In vitro studies of the combination of imatinib mesylate (Gleevec) and arsenic trioxide (Trisenox) in chronic myelogenous leukemia. Exp. Hematol. 30(7), $729-737$.

113. Kano, Y., Akutsu, M., Tsunoda, S., Mano, H., Sato, Y., Honma, Y., and Furukawa, Y. (2001) In vitro cytotoxic effects of a tyrosine kinase inhibitor STI571 in combination with commonly used antileukemic agents. Blood 97(7), 1999-2007.

114. Thiesing, J.T., Ohno-Jones, S., Kolibaba, K.S., and Druker, B.J. (2000) Efficacy of STI571, an abl tyrosine kinase inhibitor, in conjunction with other antileukemic agents against bcr-abl-positive cells. Blood 96(9), 3195-3199.

115. Gardembas, M., Rousselot, P., Tulliez, M., Vigier, M., Buzyn, A., Rigal-Huguet, F., Legros, L., Michallet, M., Berthou, C., Cheron, N., et al. (2003) Results of a prospective phase 2 study combining imatinib mesylate and cytarabine for the treatment of Philadelphia-positive patients with chronic myelogenous leukemia in chronic phase. Blood 102(13), 4298-4305.

116. Guilhot, F., Gardembas, M., Rousselot, P., Tulliez, M., Vigier, M., Buzyn, A., Rigal-Huguet, F., Legros, L., Michallet, M., Berthou, C., et al. (2003) Imatinib in combination with cytarabine for the treatment of Philadelphiapositive chronic myelogenous leukemia chronic-phase patients: rationale and design of phase I/II trials. Semin. Hematol. 40(2 Suppl 2), 92-97.

117. Komarova, N.L. and Wodarz, D. (2005) Drug resistance in cancer: principles of emergence and prevention. Proc. Natl. Acad. Sci. U. S. A. 102(27), 9714-9719.

\section{This article should be cited as follows:}

Burgess, M.R. and Sawyers, C.L. (2006) Treating imatinib-resistant leukemia: the next generation targeted therapies. TheScientificWorldJOURNAL 6, 918-930. DOI 10.1100/tsw.2006.184. 


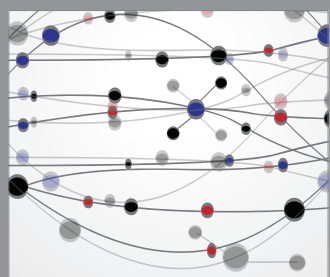

The Scientific World Journal
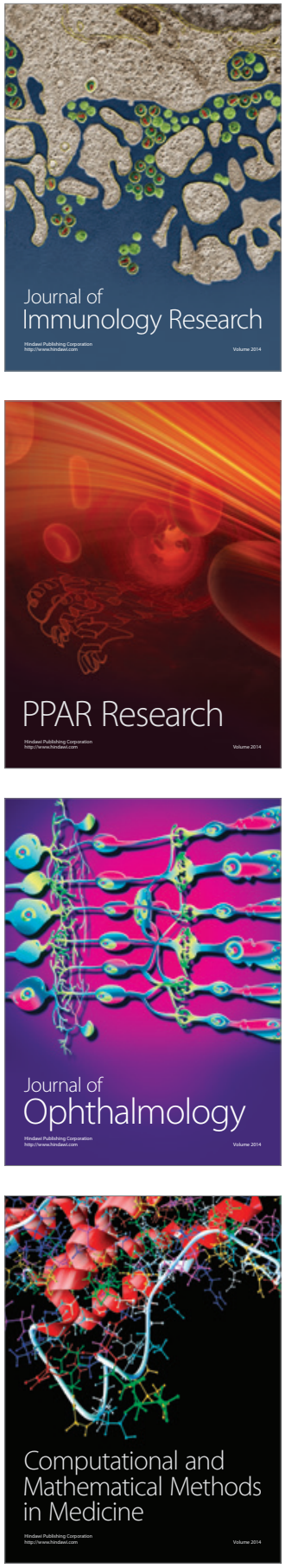

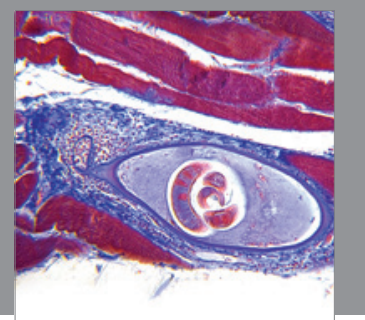

Gastroenterology

Research and Practice
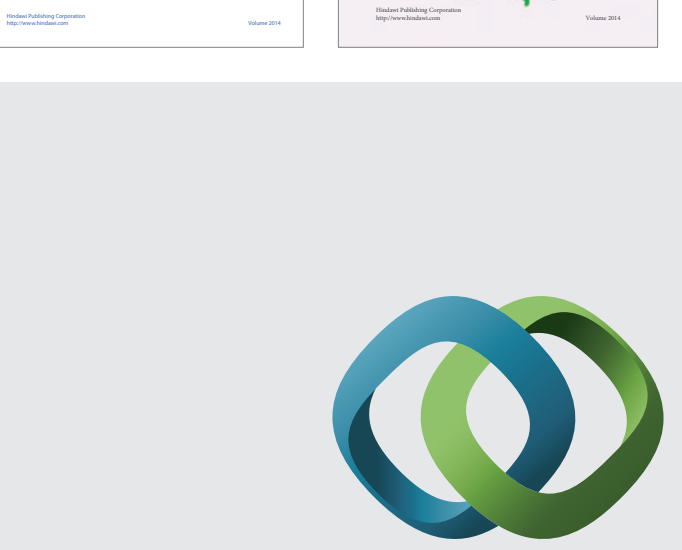

\section{Hindawi}

Submit your manuscripts at

http://www.hindawi.com
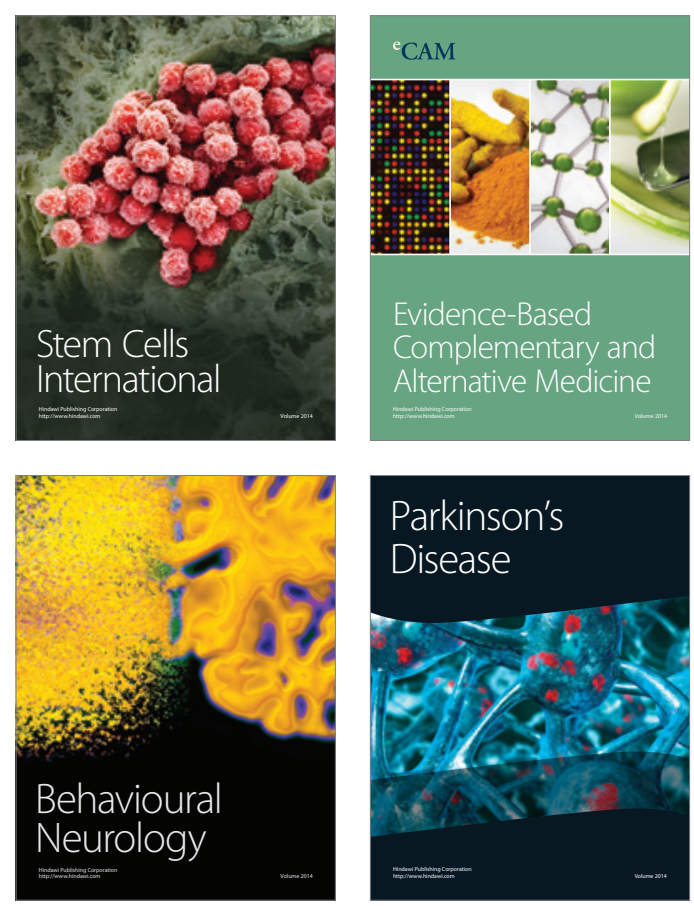

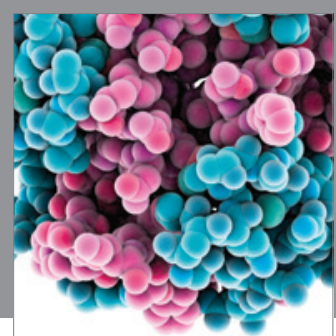

Journal of
Diabetes Research

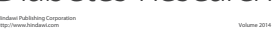

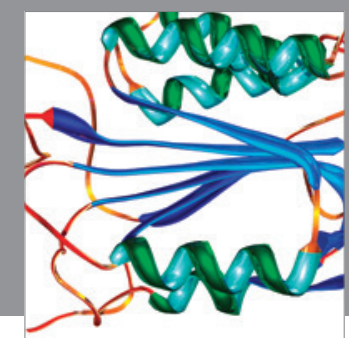

Disease Markers
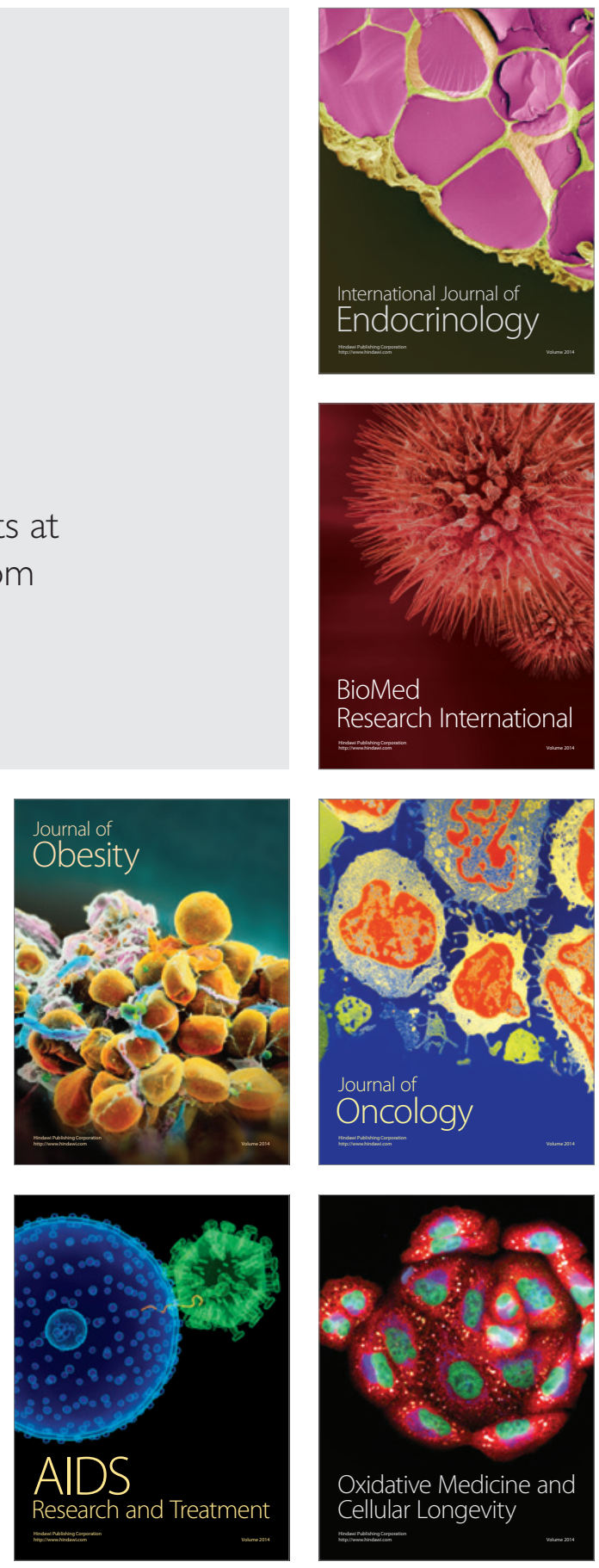